\title{
Many specialists for suppressing cortical excitation
}

\author{
Andreas Burkhalter* \\ Department of Anatomy and Neurobiology, Washington University School of Medicine, St. Louis, MO, USA
}

Cortical computations are critically dependent on GABA-releasing neurons for dynamically balancing excitation with inhibition that is proportional to the overall level of activity. Although it is widely accepted that there are multiple types of interneurons, defining their identities based on qualitative descriptions of morphological, molecular and physiological features has failed to produce a universally accepted 'parts list', which is needed to understand the roles that interneurons play in cortical processing. A list of features has been published by the Petilla Interneurons Nomenclature Group, which represents an important step toward an unbiased classification of interneurons. To this end some essential features have recently been studied quantitatively and their association was examined using multidimensional cluster analyses.

Edited by:

Javier DeFelipe, Cajal Institute (CSIC), Spain

Reviewed by:

Kathleen S. Rockland, RIKEN Brain

Science Institute, Japan

Patrick R. Hof, Mount Sinai School

of Medicine, USA

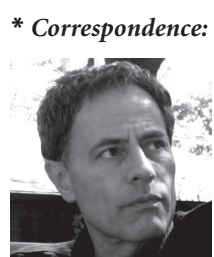

Andreas Burkhalter studied Zoology at the University of Zürich where he worked with Rüdiger Wehner on ant navigation. He obtained his Ph.D. with Michel Cuenod at the Brain Research Institute in Zürich. He then moved to the Caltech, where he was a postdoctoral student of David Van Essen and collaborator of Larry Katz. He then joined the group of Robert Baughman at Harvard University. In 1985 he joined the faculty at Washington University, where he is currently Professor. Burkhalter's laboratory studies the functional organization of areas in mouse visual cortex.

burkhala@pcg.wustl.edu

These studies revealed at least 3 distinct electrophysiological, 6 morphological and 15 molecular phenotypes. This is a conservative estimate of the number of interneuron types, which almost certainly will be revised as more quantitative studies will be performed and similarities will be defined objectively. It is clear that interneurons are organized with physiological attributes representing the most general, molecular characteristics the most detailed and morphological features occupying the middle ground. By themselves, none of these features are sufficient to define classes of interneurons. The challenge will be to determine which features belong together and how cell type-specific feature combinations are genetically specified.

Keywords: cerebral cortex, interneurons, GABAergic neurons, inhibition

\section{INTRODUCTION}

The cerebral cortex does not reveal its secrets easily. To the naked eye it appears as little more than a plain sheet of gray matter around the forebrain, and yet it is considered the cardinal achievement of evolution (Goldman-Rakic and Rakic, 1991). All mammals depend on it, so much that in the words of David Hubel and Torsten Wiesel 'a man without a cortex is almost a vegetable, speechless, sightless [and] senseless' (Hubel and Wiesel, 1979). The cortex's ability to support sensory perception, reasoning, planning and execution of behaviors is thought to be embodied in a canonical circuit that is constructed from excitatory and inhibitory neurons with similar gene expression patterns across functionally distinct areas (Douglas and Martin, 2007a; Sugino et al., 2006). This elemental circuit consists of local recurrent excitatory and inhibitory connections within and between layers, which are capable of generating such diverse properties as direction selectivity for visual motion in primary visual cortex and eye movement commands in the frontal eye field (Douglas and Martin, 1991; Heinzle et al., 2007). The key feature of this circuit is that most of its excitatory drive is generated by local recurrent connections within cortex, whereas the connections that carry sensory inputs from the outside world are relatively sparse (Ahmed et al., 1994; Binzegger et al., 2004). The ingenuity of this design is that weak afferent inputs are amplified by local positive feedback, which selects stimu- 
lus features that resonate with response profiles represented in the strengths of recurrent excitatory connections (Douglas and Martin, 2007b). The potential risk of this organization is that it generates runaway excitation and limits stimulus selectivity. An effective solution to this problem is to dynamically suppress excitation by inhibition that is proportional to the overall level of activity. This role is played by aspiny, GABAergic 'local circuit neurons' (Rakic, 1976), which account for only 10-20\% of cortical neurons (Beaulieu, 1993), but make up for their underrepresentation with a rich morphological, electrophysiological and molecular diversity (Markram et al., 2004), suggesting that synaptic inhibition acts in many different ways. This notion is strongly supported by studies in the hippocampus, in which at least 16 distinct types of interneurons have been identified that play specific roles in the timing and synchronization of excitatory pyramidal cell activity (Jinno et al., 2008; Klausberger and Somogyi, 2008; Somogyi and Klausberger, 2005). Some of these interneurons generate different forms of perisomatic inhibition and have been implicated in epilepsy and anxiety disorders (Freund and Katona, 2007). Others preferentially target pyramidal cell dendrites and appear to specialize in modulating synaptic integration (Somogyi and Klausberger, 2005). Compared to the hippocampus, classification of interneurons in the less neatly laminated cerebral cortex is lagging behind. However, gene expression studies and developmental analyses of cell fate specification strongly suggest that cerebral cortex contains multiple distinct classes of interneurons, which are born at specific locations and times and that dysfunction of inhibitory systems are linked to pathologies such as schizophrenia, autism and Tourette syndrome (Butt et al., 2008; Huang et al., 2007; Kalanithi et al., 2005; Lewis and GonzalezBurgos, 2008; Sugino et al., 2006; Tabuchi et al., 2007; Wonders and Anderson, 2006; Yuste, 2005). A clearer picture of these interneuron classes is slowly beginning to emerge due to advances in quantitatively describing morphological, physiological and molecular features and applying multidimensional cluster analyses for detecting significant associations between these features. Here, we discuss how some of these cell types were identified in the cerebral cortex and how they modulate excitation at different target locations, times and levels of activation.

A morphologically and physiologically heterogeneous population of

GABAergic neurons, which have mostly short locally projecting axons and rarely make long-range connections between different cortical areas.

\section{DIFFERENT TYPES OF INTERNEURONS MORPHOLOGICAL PROPERTIES}

Interneurons were first classified by Ramon y Cajal as 'short axon cells' in Golgi studies of human visual cortex (Ramón y Cajal, 1899; described in DeFelipe and Jones, 1988), long before it became known that most of them use GABA as inhibitory transmitter (DeFelipe, 2002; Houser et al., 1984). In the outgoing 19th century it was thought that the axons of 'short axon cells' never leave gray areas or send axons through white matter (Lenhossék, 1895; described in Rakic, 1976). More recently, however, we have learned of exceptions, which make long-range connections and send axons through white matter tracts (Higo et al., 2007; McDonald and Burkhalter, 1993; Peters et al., 1990; Tomioka and Rockland, 2007; Tomioka et al., 2005). However, the axons of most interneurons that have been reconstructed after Golgi staining or dye-filling terminate within the home area of the cell body. The list includes cells with chandelier, large basket, nest basket, small basket (i.e., clutch cells; Kisvárday, 1992), double bouquet, bipolar, bitufted, Martinotti and neurogliaform (i.e., spiderweb or dwarf cells; Ramón y Cajal, 1904) morphologies (DeFelipe, 2002; Fairén et al., 1984; Jones, 1984; Jones and Hendry, 1984; Lorente de No, 1992; Markram et al., 2004; Peters, 1984a,b; Somogyi and Cowey, 1984). Although these fanciful names have been used for decades, it is still debated whether they designate distinct types, whether cortex contains dozens or hundreds of different cell types or whether the morphological traits vary on a continuum (Parra et al., 1998; Stevens, 1998). The only interneurons that were consistently classified as distinct type are chandelier cells (ChCs), which single-mindedly innervate axon initial segments of pyramidal cells and are easily identified by the candle stick appearance of the terminal portion of their axons (Figure 1) (Somogyi, 1977). These GABAergic cells are unusual in yet another way, which enables them to depolarize pyramidal cells because the chloride reversal potential of the axon initial segment is more depolarized than that of the cell soma (Szabadics et al., 2006). Recently, significant progress has been made in classifying interneurons with less clear cut properties by quantitative multivariate grouping using cluster analysis of various features of somatic, dendritic and axonal morphologies including the distribution of boutons. Applying this classification, basket cells can now be distinguished based on the preferential targeting of $15-30 \%$ of their synapses to pyramidal cell somata (Figure 1) (Karube et al., 2004; Wang et al., 2002). Basket cells are further subdivided into large basket cells (LBCs) and small basket cells (SBCs) by characteristic relationships of soma size and the frequency of axonal branching (Karube et al., 2004). Nonpyramidal cells with $<10 \%$ of their boutons terminating on somata, a 


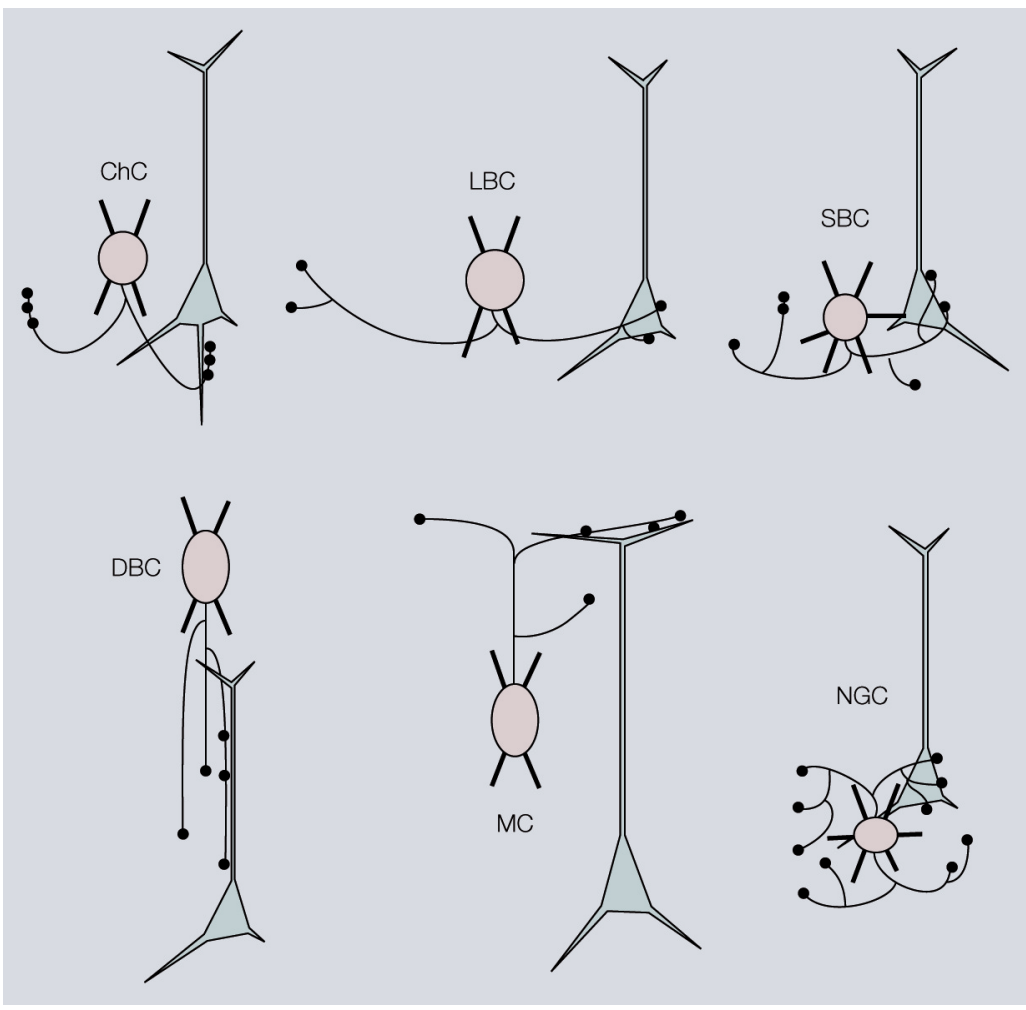

Figure 1 | Six distinct morphological types of interneurons. Diagrams showing different morphological types of interneurons (red), which were identified by cluster analyses of the subcellular distribution of axonal projections onto somata and dendrites of postsynaptic pyramidal neurons (gray). Chandelier cells (ChC), small basket cells (SBC), large basket cells (LBC), neurogliaform cells (NGFC), double bouquet cells (DBC) and Martinotti cells (MC). For examples of non-diagrammatic reconstructions of interneurons from rat somatosensory cortex and monkey prefrontal cortex see Krimer et al. (2005), Huang et al. (2007) and Ascoli et al. (2008).
Unbiased cluster analyses Statistical methods for classifying objects without preselection, using shared traits with set amounts of similarities. strong preference for dendrites and a high percentage of projections toward the white matter side of the soma, are classified as double bouquet cells (DBCs) (Figure 1) (Karube et al., 2004). Dendrite targeting neurons with a high proportion of boutons on the pial side of the cell body correspond to Martinotti cells (MCs) (Figure 1) (Dumitriu et al., 2007). Finally, neurogliaform cells (NGCs) are distinguished by their high bouton density and an axon arbor that is twice the size of the dendritic tree (Figure 1) (Karube et al., 2004). Together, these quantitative studies demonstrate that based on their axonal projection patterns there are at least six distinct morphological types of neocortical interneurons.

\section{ELECTRICAL PROPERTIES ARE NOT TIGHTLY ASSOCIATED WITH DISTINCT MORPHOLOGICAL CELL TYPES}

The pioneering intracellular recordings by McCormick et al. (1985) in rodent cerebral cortex have shown that pyramidal cells and interneurons have different passive membrane properties and spiking patterns. In these early studies, interneurons were identified as cells that respond to injections of a brief pulse of depolarizing current with a train of narrow action potentials whose interspike interval remained constant throughout the duration of the stimulus. Soon after, it was discovered that not all interneurons exhibit such fast spiking properties and that many cells show spike frequency adaptation, which is also found in pyramidal cells (Connors and Gutnick, 1990; Kawaguchi, 1993). These non-fast spiking interneurons were then further subdivided into cells in which the onset of the initial action potential is delayed (i.e., late spiking), a spike train begins with a brief burst (i.e., bursting nonpyramidal cells or low threshold neurons), or the steady-state response is irregular (Karube et al., 2004; Kawaguchi and Kubota, 1997). More recently, all of these properties were integrated in a scheme that provides an even more detailed subclassification into fast spiking cells (with continuous, delayed and stuttering firing properties), non-adapting non-fast spiking neurons (with bursting and continuous firing properties), adapting cells (with bursting, continuous and delayed firing properties), irregular spiking cells (which fire single or phasic bursts) and cells with accelerating spike rates (Gupta et al., 2000; Markram et al., 2004). This scheme turned out to be extremely useful for describing different firing properties, however it was immediately recognized that a more definitive cell type classification based on electrophysiological features requires unbiased cluster analyses. Such analyses have recently been performed in visual cortex of anesthetized cats and in slices of monkey dorsolateral prefrontal cortex. These studies revealed fast spiking and non-fast spiking cells, which could be further subclassified into cells with regular spiking (i.e., broad action potentials and spike frequency adaptation) and intermediate spiking (IS) (i.e., narrow action potentials and spike frequency adaptation) properties (Figure 2) (Krimer et al., 2005; Nowak et al., 2003). Dye-filling of recorded neurons showed unambiguously that ChCs have fast spiking properties (Krimer et al., 2005). However, the electrophysiological classification did not cleanly distinguish between basket cells, DBCs and NGCs. Despite these shortcomings, the study by Krimer et al. (2005) shows a lax exclusion rule by which fast spiking properties are strongly associated with basket and ChC morphologies, IS properties are preferentially associated with cells that have vertically oriented axons (i.e., DBCs, MCs), whereas NGCs never express fast spiking properties (Figure 2). Although this classification represents progress, the discrimination of less than a handful of distinct electrophysiological 


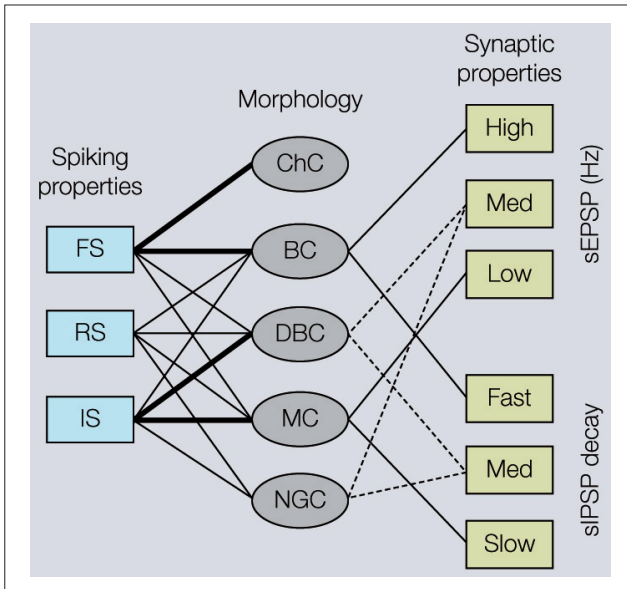

Figure 2 | Associations of electrophysiological and morphological properties of interneurons based on cluster analyses. Left side: Fast spiking (FS) properties (i.e., narrow action potentials, non-accommodating) are strongly linked (indicated by thick lines) to chandelier cells $(\mathrm{ChC})$ and basket cells $(\mathrm{BC})$. Relatively few (indicated by thin lines) interneurons show regular spiking (RS) properties (i.e., broad action potentials, accommodating), which are typically found in pyramidal cells. Intermediate spiking (IS) properties (i.e., narrow action potentials, accommodating) are strongly associated with interneurons that have vertically oriented axons (e.g., double bouquet cells (DBC) and Martinotti cells (MC)). Neurogliaform cells (NGC) never express FS properties. Right side: $\mathrm{BCs}$ receive high amplitude spontaneous excitatory postsynaptic potentials (SEPSP) and generate fast decaying spontaneous inhibitory postsynaptic potentials (sIPSPs) Putative DBCs and/or NGCs receive medium amplitude sEPSPs and more slowly decaying sIPSPs. Notice, because the cells have only been identified by the absence of $\mathrm{BC}$ and $\mathrm{MC}$ morphologies, the associations are indicated by dashed lines. MCs receive low amplitude SEPSPs and generate slowly decaying sIPSPs.

classes is no match for the 14 types proposed from qualitative evaluations by Markram et al. (2004). One way forward is to abandon subjective classification and use multidimensional hierarchical cluster analyses of quantitatively defined morphological, electrical and molecular parameters outlined by the Petilla Interneuron Nomenclature Group (Ascoli et al., 2008). The potential limitation of this approach is that cluster algorithms tend to impose structure to data sets, whether it exists or not. This highlights the importance of choosing the correct sets and weights of parameters as well as cutoffs for linkage steps. Making these determinations will require analytical tools for finding the most significant clusters with some iterative procedure for randomly varying the weights of individual parameters and entire sets of features. For this analysis to succeed it will be important to study interneurons that have not been pre-selected for particular features and to perform the grouping in a high-dimensional parameter space.

A different approach was recently used by $\mathrm{Ma}$ et al. (2006), who studied a pre-selected group of somatostatin (SOM)-expressing interneurons in mouse somatosensory cortex, which revealed that these cells fall into two separate groups: stuttering cells, which project mainly to layer 4 and low threshold bursting MCs. Using a similar strategy, Dumitriu et al. (2007) have determined the synaptic properties of mouse visual cortical neurons, which express the green fluorescent protein in parvalbumin (PV)-, SOM- and neuropeptide $\mathrm{Y}$ (NPY) immunoreactive neurons and found that PV-expressing basket cells, SOM-expressing MCs and NPY-expressing cells, with neither basket nor MC morphologies, can be distinguished based on differences in the amplitude and kinetics of spontaneous excitatory postsynaptic potentials of their inputs and spontaneous inhibitory synaptic potentials of their outputs (Figure 2). Although, these studies are highly suggestive of distinct electrophysiological types, it is important to note that the classification was done in preselected populations of interneurons and may differ from classifications derived by unbiased sampling of the entire population of GABAergic neurons.

\section{MOLECULAR PROPERTIES ARE NOT TIGHTLY ASSOCIATED WITH DISTINCT MORPHOLOGICAL AND ELECTROPHYSIOLOGICAL CELL TYPES}

The vast majority of cerebral cortical interneurons use $\gamma$-amino butyric acid as inhibitory transmitter and are therefore considered GABAergic (Houser et al., 1984). GABAergic neurons differ genetically from glutamatergic excitatory pyramidal neurons, and comprise different populations that express different sets of genes (Esumi et al., 2008; Sugino et al., 2006). This heterogeneity has long been recognized by the expression and colocalization of many different peptides and calcium binding proteins (DeFelipe, 1993). Considering the enormous variety of interneuron morphologies (Lorente de No, 1992) and electrophysiological properties (Markram et al., 2004) it is, however, surprising that a short list of only six immunocytochemically identified molecules, which includes PV, calretinin (CR), SOM, vasointestinal polypeptide (VIP), cholecystokinin (CCK) and the NMDA receptor binding protein, $\alpha$-actinin-2, accounts for $95 \%$ of GABAergic neurons in the cerebral cortex of VGAT (i.e., vesicular GABA transporter)-Venus (i.e., fluorescent marker)expressing transgenic rats (Uematsu et al., 2008). A similar list, which in addition includes NPY and the enzyme choline acetyltransferase (ChAT) 
but excludes $\alpha$-actinin-2, was found to account for $>90 \%$ of GABA immunostained neurons in mouse visual cortex (Gonchar et al., 2008). These studies support the well established notion that the expression of calcium binding proteins and peptides are effective tools for classifying interneurons (DeFelipe, 1993, 1997). The problem with this approach, however, is that different markers are often coexpressed by the same interneurons and that the expressions depend on species, location, age and neuronal activity (DeFelipe, 1993; DeFelipe et al., 2002; Gonchar and Burkhalter, 1997; Gonchar et al., 2008; Jiao et al., 2006), making it a tricky classification tool.

The most distinct group is represented by PV-immunoreactive neurons, that were discovered by Celio (1986) and which in rodents account for 40-50\% of GABAergic neurons (Gonchar and Burkhalter, 1997; Gonchar et al., 2008; Kubota et al., 1994). A much higher percentage (74\%) of PV neurons was found in macaque visual cortex (DeFelipe et al., 1999; Van Brederode et al., 1990). An important property of PV neurons is that they do not stain with antibodies against CR, SOM, VIP, CCK, NPY, ChAT and $\alpha$-actinin-2 (Gonchar et al., 2008; Uematsu et al., 2008) (Figure 3). However, coexpression of calbindin (CB), corticotropin releasing factor and substance P (SP) immunoreactivity in subsets of PV neurons suggests that PV neurons are chemically heterogeneous (Gonchar and Burkhalter, 1997; Karube et al., 2004; Kubota et al., 1994; Kawaguchi and Kubota, 1993; Lewis and Lund, 1990; Vruwink et al., 2001) (Figure 3). Heterogeneity within the PV population was long known to exist by the presence of basket cell and ChC morphologies, and the expression of non-accommodating fast spiking and burst firing properties (Blatow et al., 2003; Chattopadhyaya et al., 2004; DeFelipe et al., 1989; Zaitsev et al., 2005).

In contrast to the very limited overlap of PV with other immunocytochemically detected substances, the overlap between PV mRNA and mRNAs of other calcium binding proteins and peptides is much more extensive (Cauli et al., 1997; Toledo-Rodriguez et al., 2005; Wang et al., 2002) (Figure 3), indicating that in many neurons PV mRNA is not translated. Thus, the genotypic and phenotypic molecular classification schemes are not interchangeable.

Unlike PV-immunopositive neurons, PV-immunonegative cells coexpress a much broader panel of calcium binding proteins and peptides (Gonchar and Burkhalter, 1997; Kubota et al., 1994). Initial double immunolabeling studies in rat frontal and visual cortex have shown that SOM and CR, SOM and VIP, NPY and

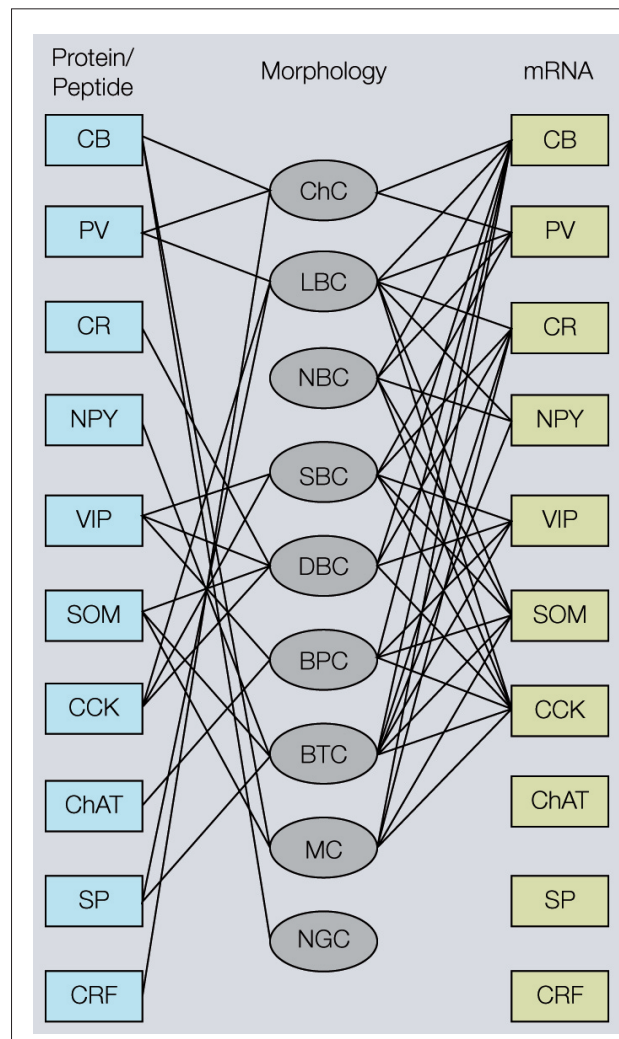

Figure 3 | Associations of molecular (protein, mRNA) and morphological properties of interneurons. Left side: Immunocytochemical expression of commonly used markers [i.e., calbindin (CB), parvalbumin (PV), calretinin (CR), neuropeptide $Y(N P Y)$, vasointestinal polypeptide (VIP), somatostatin (SOM), cholecystokinin (CCK), choline acetyltransferase (ChAT), substance $\mathrm{P}(\mathrm{SP})$ corticotropin releasing factor (CRF)] in different morphological types of interneurons [i.e., chandelier cells (ChC), large basket cells (LBC), nest basket cells (NBC), small basket cells (SBC), bipolar cells (BPC), bitufted cells (BTC), Martinotti cells (MC), neurogliaform cells (NGC)]. Right side: mRNAs expression in different types of interneurons. Notice that most substances are coexpressed in multiple cell types and that the overlap in mRNA expression is much more extensive than immunostaining, suggesting that antibody staining is a more discriminating classification tool. Thus, genotypic and phenotypic molecular classification schemes are not interchangeable.

CCK constitute largely non-overlapping populations (Gonchar and Burkhalter, 1997; Kubota et al., 1994). However, recent double- and triple immunolabeling studies in adult mouse cerebral cortex have found that, unlike in rat, SOM and $\mathrm{CR}$ are coexpressed in a substantial percentage (20-40\%) of GABAergic neurons, which confirms the notion that molecular expression patterns are species-specific (Gonchar et al., 2008; Halabisky et al., 2006; Hof et al., 1999; Miyoshi et al., 2007; Xu et al., 2006). Furthermore, these studies have shown extensive overlap between 
SOM and VIP, SOM and SP, VIP and ChAT, and NPY and CCK (Gonchar et al., 2008; Karube et al., 2004; Miyoshi et al., 2007; von Engelhardt et al., 2007; Wolansky et al., 2007; Xu et al., 2006). Importantly, however, the overlap of markers for example in mouse visual cortex is incomplete, and the immunocytochemical colocalization of VIP + NPY, VIP + CCK, SOM + CCK, $\mathrm{SOM}+\mathrm{ChAT}$ and NPY + ChAT has never been observed, suggesting some kind of exclusion rule (Gonchar et al., 2008). A slightly different pattern exists in rat primary motor cortex, where Karube et al. (2004) found a small amount of overlap between VIP and CCK. Although considerable advances in cell type identification and fate mapping (see, e.g., Wonders and Anderson, 2006) can be credited to antibody labeling of various proteins and peptides, the usefulness of this approach for cell type classification is limited due to the finite number of marker combinations that can be tested in single cells. Clearly, more definitive answers can be expected from gene-expression profiling and analyses of the combinatorial code of transcription factor expression that may ultimately define different cell types (Flames et al., 2007; Nelson et al., 2006; Yuste, 2005). Based on the most extensive quantitative immunohistochemical studies presently available, we conclude that there are at least three different subgroups of PV neurons and 12 subgroups of non-PV cells (Gonchar et al., 2008; Kubota et al., 1994; Lewis and Lund, 1990; Vruwink et al., 2001).

In contrast, classification based on mRNA expression is much less effective. In fact, the overlap of mRNA expression revealed by single cell multiplex RT-PCR is so extensive that it shows colocalization of PV with CR, VIP, SOM, NPY and CCK, which has never been observed with immunostaining. Thus, message expression fails to classify interneurons even broadly into PV-positive and PV-negative groups (Cauli et al., 2000; Condé et al., 1994; Demeulemeester et al., 1991; Gonchar and Burkhalter, 1997; Gonchar et al., 2008; Kawaguchi and Kubota, 1997; Kubota et al., 1994; Toledo-Rodriguez et al., 2005; Wang et al., 2002). Nevertheless, clear trends in mRNA expression profiles have emerged, which show significantly lower probabilities for the coexpression of PV + SOM, PV + VIP and SOM + VIP (ToledoRodriguez et al., 2005).

VIP immunolabeling and mRNA was shown to be preferentially expressed in SOM-negative SBCs, DBCs, bipolar cells (BPCs) and bitufted cells (BTCs) with vertically descending axons (Kawaguchi and Kubota, 1996, 1997; ToledoRodriguez et al., 2005) (Figure 3). In contrast, VIP mRNA tends to be excluded from LBCs, nest basket cells (NBCs) and MCs (Toledo-Rodriguez et al., 2005; Wang et al., 2002) (Figure 3). The morphological diversity of VIP-expressing neurons is mirrored by the electrophysiological heterogeneity, which includes accommodating, bursting and irregular spiking properties (Cauli et al., 2000; Kawaguchi and Kubota, 1996; Toledo-Rodriguez et al., 2005; Uematsu et al., 2008). Whether the different morphological and electrophysiological phenotypes represent distinct cell classes remains to be established with unbiased cluster analyses. However, the coexpression of several molecules (i.e., VIP + NPY, VIP + SOM, VIP + CR, $\mathrm{VIP}+\mathrm{ChAT}$, VIP + SOM + CR; Gonchar et al., 2008; Toledo-Rodriguez et al., 2005) that are known to influence neuronal excitabilities and vascular tone (Baraban and Tallent, 2004; Cauli et al., 2004; Schwaller et al., 2002) suggest that VIP neurons play multiple different roles in cortical processing and blood flow regulation.

SOM immunolabeling and mRNA was found in NBCs, DBCs, BTCs, BPCs with ascending axons and MCs that do not express VIP, but tends to be excluded from LBCs and SBCs (Kawaguchi and Kubota, 1996, 1997; Toledo-Rodriguez et al., 2005; Wang et al., 2002, 2004) (Figure 3). Most SOM-expressing neurons have accommodating firing properties, but stuttering and bursting firing patterns have also been observed (Cauli et al., 1997, 2000; Goldberg et al., 2004; Kawaguchi and Kubota, 1996; Wang et al., 2002, 2004). Thus, except for the preference for ascending axonal projections, few differences were found between SOM and VIP neurons and the identification of subtypes of SOM neurons is tentative. Recently, however cluster analyses of pre-selected GFPlabeled SOM neurons in transgenic 'GIN' mice (Oliva et al., 2000) have identified four subtypes of SOM neurons with different passive membrane properties, spiking patterns, afterhyperpolarizations and spontaneous excitatory postsynaptic currents (Halabisky et al., 2006). Furthermore, studies in two different lines of transgenic mice with GFP-labeled SOM neurons, Ma et al. (2006) have identified two additional subtypes, one with ascending projections to layer 4 and stuttering firing properties, and another that resembles MCs and fires low threshold bursts of action potentials. Finally, Xu et al. (2006) have shown that SOMexpressing MCs in mouse cerebral cortex consist of two subtypes that either coexpress CR or are CR-immunonegative (Xu et al., 2006). Additional support for the notion of multiple subtypes of MCs derives from fate mapping studies, which show that CR-immunonegative/SOM-positive cells are born before CR-immunopositive/SOM-negative neurons (Miyoshi et al., 2007). Thus, at the very 
least SOM-expressing neurons contain four and perhaps as many as six different subtypes.

Double- and triple immunolabeling studies in rat and mouse cerebral cortex have shown that significant numbers of interneurons express CR but do not coexpress SOM or VIP (Gonchar et al., 2008; Uematsu et al., 2008). Recently, these cells were shown to coexpress $\alpha$-actinin-2, exhibit neurogliaform morphologies, have late spiking properties and generate $\mathrm{GABA}_{\mathrm{A}}$ and $\mathrm{GABA}_{\mathrm{B}}$ receptor mediated inhibition (Tamás et al., 2003; Uematsu et al., 2008), suggesting that PV-negative, $\alpha$-actinin-2-positive GABAergic neurons represent a distinct type of interneuron.

CCK immunolabeling was found in GABAergic neurons of rat motor and mouse visual cortex (Gonchar et al., 2008; Karube et al., 2004; Kawaguchi and Kondo, 2002; Kubota and Kawaguchi, 1997). Studies in rat frontal cortex showed that some of these neurons in addition contain VIP and CR but that they lack NPY (Karube et al., 2004). This expression pattern differs from mouse visual cortex, in which CCK neurons were found to contain CR and NPY but do not stain for VIP (Gonchar et al., 2008). In contrast to the molecular heterogeneity, CCK neurons appear to be physiologically similar in that they uniformly express non-fast spiking, irregular firing properties (Galarreta et al., 2004; Karube et al. 2004; Kawaguchi and Kondo, 2002). Morphologically, however, CCK neurons are diverse, exhibiting small cell bodies with bipolar and bitufted dendritic arbors as well as axonal features of SBCs and LBCs (Karube et al., 2004; Kubota and Kawaguchi, 1997). Large CCK immunoreactive basket cells in rat somatosensory cortex were shown to innervate pyramidal cell somata, and similar to their PV-expressing counterparts are thought to provide perisomatic inhibition (Bodor et al., 2005). However, unlike PV neurons which express $\alpha_{1}$ GABA receptors, GABAergic transmission at CCK synapses is mediated mainly by $\alpha_{2}$ receptors (Freund and Katona, 2007). In addition, unlike the axon terminals of fast spiking PV neurons, CCK immunoreactive presynaptic terminals in contact with pyramidal neurons have a much higher failure rate and express type 1 cannabinoid receptors, which when activated by the release of endogenous cannabinoids from postsynaptic pyramidal cells, suppress inhibition (Bodor et al., 2005; Galarreta et al., 2008; Hill et al., 2007). Interestingly, both PV and CCK neurons are electrically coupled by gap junctions, which are responsible for synchronizing the activity within each population as well as among interconnected pyramidal neurons. Such synchronous network oscillations are thought to play a role in facilitating interactions between different cortical areas and in visual attention (Fries et al., 2008; Galarreta and Hestrin, 2002; Galarreta et al., 2004; Womelsdorf et al., 2007). Thus, suppression of inhibition by endocanabinoids may provide a mechanism by which CCK neurons modulate the synchrony of network oscillations (Freund and Katona, 2007).

\section{ROLE OF INTERNEURONS IN CORTICAL CIRCUITS}

There is a long way to go to understand the role of every type of interneuron in cortical processing. However, with the development of new tools the finish line has moved closer (Kuhlman and Huang, 2008). Impressive progress has already been made in regard to PV neurons and two subtypes of SOM neurons, which are the main focus here.

\section{PARVALBUMIN-EXPRESSING FAST SPIKING CELLS}

Several anatomical and physiological studies in visual, somatosensory and motor cortex of juvenile and young adult rats and cats have shown that PV-immunoreactive, fast spiking neurons play a role in mediating feedforward inhibition in thalamocortical, interlaminar and interareal circuits (Angulo et al., 1999; Beierlein et al., 2003; Gonchar and Burkhalter, 1999; Porter et al., 2001; Reyes et al., 1998; Thomson and Deuchars, 1997; Thomson et al., 2002; West et al., 2006). How this feedforward inhibitory circuit works is most completely understood in the rat thalamocortical somatosensory pathway. In this system, PV neurons receive input from thalamocortical axons (Staiger et al., 1996) and synapse onto layer 4 spiny neurons, which receive direct connections from the thalamus (White, 1978) (Figure 4). Thus, thalamocortical input evokes a brief excitatory response in spiny neurons, which is readily opposed by inhibition from PV neurons (Agmon and Connors, 1992; Zhu and Connors, 1999). In the intact rabbit somatosensory cortex, this disynaptic inhibition very effectively suppresses sustained firing of spiny neurons to input from the thalamus (Swadlow, 2003). The effectiveness of this suppression has multiple reasons. First, fast spiking neurons (i.e., putative PV neurons) receive very powerful inputs from a large number of thalamocortical axons, which makes them more excitable than spiny cells (Cruikshank et al., 2007; Gabernet et al., 2005). Second, fast spiking neurons evoke large inhibitory responses in spiny cells (Cruikshank et al., 2007; Gabernet et al., 2005). Finally, the transmission time between fast spiking neurons and spiny cells and the dynamics of excitatory 


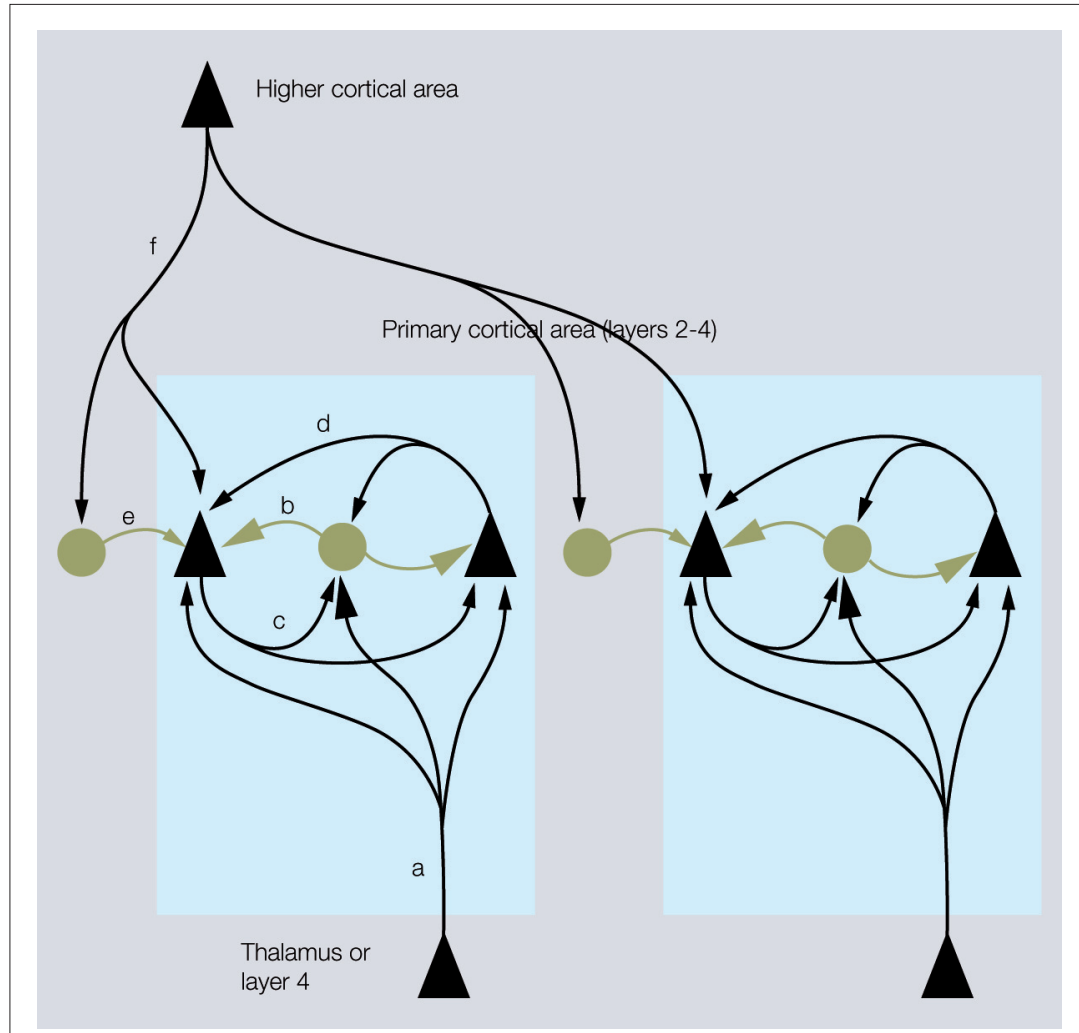

Figure 4 | Inhibitory networks involving fast spiking parvalbumin (PV)-expressing neurons in thalamocortical, interlaminar and interareal cortical circuits. Feedforward excitatory thalamocortical inputs to spiny neurons $(\mathbf{\Delta})$ and fast spiking interneurons $(\bullet)$ in layers 2-4 (a). Inputs to interneurons are stronger (large arrowheads) than inputs to spiny cells. PV neurons provide strong (large rectangular endings) feedforward inhibition (b) to spiny cells. Feedback inhibition (c) results from PV neurons that are excited by the same spiny neurons that they inhibit. These reciprocally connected spiny neuron/PV neuron pairs share common inputs (e.g., cells in layer 4 from thalamus or cells in layer 2/3 from layer 4) creating recurrent excitatory (d) and inhibitory subnetworks (contained within blue shaded boxes). 'Lateral' inhibition (e) of these subnetworks results from PV neurons that are driven by excitatory feedback connections (f) from outside the subnetworks (e.g., by layer 5 to layer $2 / 3$ connections or feedback from higher cortical areas). Notice that 'lateral' inhibition is weaker (small rectangular endings) than feedforward and feedback inhibition and impinges on multiple subnetworks.
Fast spiking PV-immunoreactive interneurons in layer $2 / 3$ of rat and cat visual cortex receive strong excitatory input from layer 4 and provide feedforward inhibition to neighboring layer $2 / 3$ pyramidal cells (Dantzker and Callaway, 2000; Thomson et al., 2002). Paired recordings from fast spiking neurons (i.e., putative PV neurons) and pyramidal cells in layer $2 / 3$ of rat visual cortex have shown that these feedforward inhibitory connections are preferentially received by pyramidal neurons that project back to the fast spiking neuron that provides the inhibitory input (Yoshimura and Callaway, 2005). This demonstrates that inhibition by fast spiking neurons is applied to the same pyramidal cells that supply their excitation, which is the hallmark of feedback inhibitory circuits (Figure 4). Importantly, these feedback inhibitory circuits are formed preferentially between fast spiking cells and layer $2 / 3$ pyramidal cells, which are reciprocally connected and share common excitatory feedforward and horizontal inputs from layer 4 and layer $2 / 3$ neurons (Yoshimura and Callaway, 2005; Yoshimura et al., 2005). These results suggest that specific sets of fast spiking neurons are owned by individual excitatory subnetworks, and that these $\mathrm{PV}$-expressing interneurons play a role in setting the gain and timing of responses within neuronal populations that may share similar stimulus selectivities (Ohki and Reid, 2007).

Unlike the subnetwork-specific feedforward excitatory input from layer 4 to reciprocally interconnected layer $2 / 3$ pyramidal cells and fast spiking neurons, excitatory feedback input from layer 5 in rat visual cortex is not specifically targeted to individual layer $2 / 3$ subnetworks, but is distributed to pyramidal cells and fast spiking neurons, regardless of whether these cells are directly interconnected (Yoshimura and Callaway, 2005). This means that excitatory feedback connections have access to several different excitatory subnetworks and activate feedforward inhibition to pyramidal cells, which do not provide excitation to fast spiking cells. Yoshimura and Callaway (2005) have shown that such non-reciprocated 'lateral' inhibition (Figure 4) is driven from outside the subnetwork and is much weaker than feedforward and feedback inhibition originating from within the subnetwork. Similar to layer 5, higher cortical areas are an important source of excitatory feedback input to layer $2 / 3$ of primary visual cortex (Coogan and Burkhalter, 1993). The main inhibitory targets of this input are PV-immunoreactive neurons (Gonchar and Burkhalter, 1999, 2003; Yamashita et al., 2003), suggesting that these cells provide weak 'lateral' inhibition to pyramidal neurons (Yoshimura and Callaway, 2005). Indeed, 
studies in rat and mouse visual cortex have shown that in interareal feedback circuits, excitation is opposed by much weaker inhibition than in interareal feedforward circuits, suggesting that the balance between excitation and inhibition is tipped toward depolarization, which may increase the gain of sensory inputs to primary visual cortex by top-down connections from higher visual areas (Dong et al., 2004a; Shao and Burkhalter, 1996). That fast spiking interneurons play a key role in balancing recurrent excitation and inhibition, was directly demonstrated in ferret visual cortex (Shu et al., 2003).

\section{ROLE OF SOMATOSTATIN-EXPRESSING NEURONS IN FEEDFORWARD INHIBITION}

Until recently, it was widely held that fast spiking, PV-immunoreactive neurons are solely responsible for thalamocortical feedforward inhibition (Daw et al., 2007; Sun et al., 2006). Recordings from GFP-labeled SOM-immunopositive neurons (CB-immunonegative, NPY-immunonegative) in the somatosensory barrel cortex of the X94 line of transgenic mice, however, show that cells in layer 5 with dense projections to layer 4 receive direct thalamocortical input, suggesting that they play a role in feedforward inhibition of thalamo-recipient spiny neurons in layer 4 (Tan et al., 2008). Unlike PV neurons, whose synaptic responses to repetitive thalamocortical inputs are depressing and transient, responses of GFPexpressing X94 SOM neurons are strongly facilitating and produce sustained firing (Tan et al., 2008). As a result of these dynamic properties, PV neuron-mediated feedforward inhibition is most effective at low frequencies, whereas SOM neuron-mediated inhibition is strongest at high frequencies. Because PV neurons preferentially innervate somata whereas SOM neurons are preferentially targeted to dendrites (DiCristo et al., 2004; Dumitriu et al., 2007; Karube et al., 2004), the frequency-dependent switch reflects a transition from somatic to dendritic inhibition, thereby gaining control over the integration of sensory inputs with recurrent intracortical excitation.

\section{ROLE OF MARTINOTTI CELLS IN FEEDBACK INHIBITION}

Paired recordings have shown that many different types of interneurons including fast-, late-, low threshold-, irregular- and burst spiking cells (Beierlein et al., 2003; Blatow et al., 2003; Chu et al., 2003; Galarreta et al., 2004; Gupta et al., 2000; Reyes et al., 1998; Thomson and Deuchars, 1997; Thomson et al., 2002), receive inputs from pyramidal neurons and generate feedback inhibition in the same cells that excites them. Two recent studies in rat somatosensory cortex have shown that one of these cell types, SOMimmunoreactive MCs, are selectively activated by action potential trains from single pyramidal cells and distribute inhibition to several neighboring pyramidal neurons (Kapfer et al., 2007; Silberberg and Markram, 2007). In sharp contrast, activation of recurrent inhibition by fast spiking PV-expressing neurons, whose connectivity rate with pyramidal cells is very high (Thomson and Lamy, 2007), requires inputs from more than a single pyramidal cell (Kapfer et al., 2007; Silberberg and Markram, 2007; Wang et al., 2002). The low threshold of MC activation and its high inhibitory impact is due to the high degree of convergence, divergence and reciprocity of connections with pyramidal neurons. In fact, the connectivity pattern is so ingenious that synchronous excitatory input from two pyramidal neurons leads to a supralinear increase in the number of recruited MCs (Kapfer et al., 2007). A distinctive feature of the inhibitory feedback circuit between pyramidal neurons and MCs is that inhibition of pyramidal cells is targeted to the distal dendritic tufts in layer 1, suggesting that it is not involved in gain control of firing but in the modulation of dendritic excitability (Silberberg and Markram, 2007). Because layer 1 is an important target of interareal feedback connections (Coogan and Burkhalter, 1993; Dong et al., 2004b), inhibition by MCs may therefore modulate the impact of global top-down influences on the processing of local information within the columnar network.

\section{CONCLUSIONS}

An impressive body of work on the morphological, electrophysiological and molecular properties of qualitatively pre-selected populations of interneurons suggests that cerebral cortex contains multiple types of interneurons. Recent, unbiased quantitative analyses have revealed that axon projections are powerful classification parameters for identifying interneurons into LBCs and SBCs, ChCs, NGCs, DBCs and MCs. However, quantitative definitions of electrical excitabilities were found to be only loosely associated with specific morphological properties, which means that fast spiking properties are not exclusively expressed by ChCs and basket cells and spike accommodation is not a unique property of DBCs, MCs and NGCs. Similarly, cluster analyses have shown that electrical parameters only partially match molecular expression patterns, such that fast spiking properties are not only found in PV-expressing neurons and spike accommodation is not a surrogate property of 
all PV-negative neurons. Immunolabeling studies have shown that calcium binding protein, peptide and transmitter synthesizing enzyme expressions extensively overlap and that the staining patterns vary across development, location and species. However, in adult mouse visual cortex, PV is never coexpressed with SOM, CR, VIP, ChAT, NPY and CCK. Further, VIP does not associate with NPY and CCK. SOM does not colocalize with CCK and ChAT, and NPY is absent in ChAT-expressing cells. Importantly, these exclusion rules do not apply to mRNAs, whose expressions are much more promiscuous. Thus, genotypic and phenotypic molecular classification schemes are not interchangeable. Clearly, we are far from being able to unequivocally identify different types of interneurons. There is however, great promise that this goal may be achieved through unbiased multidimensional cluster analyses of morphological, electrical and molecular features listed by the Petilla Interneurons Nomenclature Group (Ascoli et al., 2008). Once the players are defined, an important next step will be to develop a better understanding of how local inhibitory circuits are integrated into interareal cortical networks.

\section{ACKNOWLEDGEMENTS}

I would like to thank my colleagues Hongwei Dong, Enquan Gao, Yuri Gonchar, Ekaterina Hatch, Jeanne M. Nerbonne, Katia Valkova, Quanxin Wang and Jun Xiao for their collaboration and discussion. Financial support was generously provided by NIH grants EY05935, EY016184 and the McDonnell Center for Higher Brain Function.

\section{REFERENCES}

Agmon, A., and Connors, B. W. (1992). Correlation between intrinsic firing patterns and thalamocortical synaptic responses of neurons in mouse barrel cortex. J. Neurosci. 12, 319-329.

Ahmed, B., Anderson, J. C., Douglas, R. J., Martin, K. A. C., and Nelson, J. C. (1994). Polyneuronal innervation of spiny stellate neurons in cat visual cortex. J. Comp. Neurol. 341, 39-49.

Angulo, M. C., Rossier, J., Staiger, J. F., and Audinat,E. (1999). Postsynaptic glutamate receptors and integrative properties of fast-spiking interneurons in the rat neocortex. J. Neurophysiol. 82, 1295-1302.

Ascoli, G. A., Alonso-Nanclares, L., Anderson, S. A., Barrinuevo, G., Benavides-Piccone, R., Burkhalter, A. et al. (2008). Petilla terminology: nomenclature of features of GABAergic interneurons of the cerebral cortex. Nat. Rev. Neurosci. 9, 1-12.

Baraban, S. C., and Tallent, M. K. (2004). Interneurons diversity series: Interneuronal neuropeptides - endogenous regulators of neuronal excitability. Trends Neurosci. 27, 135-142.

Beaulieu, C. (1993). Numerical data on neocortical neurons in adult rat with special reference to the GABA population. Brain Res. 609, 284-292.

Beierlein, M., Gibson, J. R., and Connors, B. W. (2003). Two dynamically distinct inhibitory networks in layer 4 of the neocortex. J. Neurophysiol. 90, 2987-3000.

Binzegger, T., Douglas, R. J., and Martin, K. A.C. (2004). A quantitative map of the circuit of primary visual cortex. J. Neurosci. 24, 8441-8453.

Blatow, M., Rozov, A., KAtona, I., Hormuzi, S. G., Meyer, A.,
Whittington, M. A., Caputi, A., and Monyer, H. (2003). A novel network of multipolar bursting interneurons generates theta frequency oscillations in neocortex. Neuron 38, 805-817.

Bodor, A. L., Katona, I., Nyíri, G., Mackie, K., Ledent, C., Hájos, N., and Freund, T.F. (2005). Endocannabinoid signaling in rat somatosensory cortex: laminar differences and involvement of specific interneuron types. $J$. Neurosci. 25, 6845-6856.

Butt, S. J. B., Sousa, V. H., Fuccillo, M. V, Hjerling-Leffler, J., Miyoshi, G., Kimura, S., and Fishell, G. (2008). The requirement of $N k \times 2-1$ in the temporal specification of cortical interneuron subtypes. Neuron 59, 722-732.

Cauli, B., Audinat, E., Lambolez, B., Angulo, M.C., Ropert, N., Tsuzuki, K., Hestrin, S., and Rossier, S. (1997). Molecular and physiological diversity of cortical nonpyramidal cells. J. Neurosci. 17, 3894-3906.

Cauli, B., Porter, J. T., Tsuzuki, K., Lambolez, B., Rossier, J., Quenet, B., and Audinat, E. (2000). Classification of fusiform neocortical interneurons based on unsupervised clustering.Proc. Natl. Acad. Sci. USA 97, 6144-6149.

Cauli, B., Tong, X.-K., Rancillac, A., Serluca, N., Lambolez, B., Rossier, J., and Hamel, E. (2004). Cortical GABA interneurons in neurovascular coupling: relays for subcortical vasoactive pathways. J. Neurosci. 24, 8940-8949.

Celio, M. R. (1986). Parvalbumin in most $\gamma$-aminobutyric acid-containing neurons of the rat cerebral cortex. Science 231, 995-997.

Chattopadhyaya, B., Di Cristo, G., Higashiyama, H., Knott, G. W., Kuhlman, S. J., Welker, E., and Huang, J. Z. (2004). Experience and activity-dependent maturation of perisomatic GABAergic innervation in primary visual cortex during a postnatal critical period. J. Neurosci. 24, 9598-9611.

Chu, Z., Galarreta, M., and Hestrin, S. (2003). Synaptic interactions of latespiking neocortical neurons in layer 1 . J. Neurosci. 23, 96-102.

Condé, F., Lund, J. S., Jacobowitz, D. M. Baimbridge, K. G., and Lewis, D. A. (1994). Local circuit neurons immunoreactive for calretinin, calbindin D-28k or parvalbumin in monkey prefrontal cortex: distribution and morphology. J. Comp. Neurol. 341, 95-116.

Connors, B. W., and Gutnick, M. J. (1990) Intrinsic firing patterns of diverse neocortical neurons. Trends Neurosci. 13 99-104.

Coogan, T. A., and Burkhalter, A. (1993). Hierarchical organization of areas in rat visual cortex. J. Neurosci. 13, 3749-3772.

Cruikshank, S. J., Lewis, T. J., and Connors, B.W. (2007). Synaptic basis for intense thalamocortical activation of feedforward inhibitory cells in neocortex. Nat. Neurosci. 10, 462-468.

Dantzker, J.L., and Callaway, E. M. (2000). Laminar sources of synaptic input to cortical inhibitory interneurons and pyramidal neurons. Nat. Neurosci. 3 , 701-707.

Daw, M. I., Ashby, M. C., and Isaac, J. T. R. (2007). Coordinated developmental recruitment of latent fast spiking interneurons in layer IV barrel cortex. Nat. Neurosci. 10, 453-461.

DeFelipe, J. (1993). Neocortical neurons diversity: chemical heterogeneity revealed by colocalization studies of classic neurotransmitters, neuropeptides, calcium-binding proteins, and cell surface molecules. Cereb. Cortex 3, 273-289.
DeFelipe, J. (1997). Types of neurons, synaptic connections and chemical characteristics of cells immunoreactive for calbindin-D28K, parvalbumin and calretinin in the neocortex. J. Chem. Neuroanat. 14, 1-19.

DeFelipe, J. (2002). Cortical interneurons: from Cajal to 2001. Prog. Brain Res. 136, 215-238.

DeFelipe, J., Alonso-Nanclares, L., and Arellano, J. L. (2002). Microstructure of the neocortex: comparative aspects. J. Neurocytol. 31, 299-316.

DeFelipe, J., González-Albo, M. C., Del Río, R., and Elston, G. N. (1999). Distribution and patterns of connectivity of interneurons containing calbindin, calretinin, and parvalbumin in visual areas of the occipital and temporal lobes of the macaque monkey. J. Comp. Neurol. 412, 515-526.

DeFelipe, J., Hendry, S. H. C., and Jones, E. G. (1989). Visualization of chandelier cell axons by parvalbumin immunoreactivity in monkey cerebral cortex. Proc. Natl. Acad. Sci. USA 86, 2093-2097.

DeFelipe, J., and Jones, E. G. (1988). Cajal on the Cerebral Cortex. New York, Oxford University Press, pp. 139-146.

Demeulemeester, H., Arckens, L., Vandesande,F.,Orban, G.A.,Heizmann, C. W., and Pochet, R. (1991). Calcium binding proteins and neuropeptides as molecular markers of GABAergic interneurons in the cat visual cortex. Exp. Brain Res. 84, 538-544.

DiCristo, G., Di Cristo, G., Wu, C., Chattopadhyaya, B., Ango, F., Knott, G., Welker, E., Svoboda, K., and Huang, Z. J. (2004). Subcellular domain-restricted GABAergic innervation in primary visual cortex in the absence of sensory and thalamic inputs. Nat. Neurosci. 7, 1184-1186. 
Dong, H., Shao, Z., Nerbonne, J. M., and Burkhalter, A. (2004a). Differential depression of inhibitory synaptic responses in feedforward and feedback circuits between different areas of mouse visual cortex. J. Comp. Neurol. 475, 361-373.

Dong, H., Wang, Q., Valkova, K., Gonchar, Y., and Burkhalter, A. (2004b). Experience-dependent development of feedforward ad feedback circuits between lower and higher areas of mouse visual cortex. Vision Res. 44, 3389-3440.

Douglas, R. J., and Martin, K. A. C. (1991). A functional microcircuit for cat visual cortex. J. Physiol. 440, 735-769.

Douglas, R. J., and Martin, K. A.C. (2007a). Mapping the matrix: the ways of neocortex. Neuron 56, 226-238.

Douglas, R. J., and Martin, K. A. C. (2007b).Recurrent neuronal circuits in the neocortex. Curr. Biol. 17, R496-R500.

Dumitriu, D., Cossart, R., Huang, J., and Yuste, R. (2007). Correlation between axonal morphologies and synaptic input kinetics of interneurons from mouse visual cortex. Cereb. Cortex $17,81-91$

Esumi, S., Wu, S.-X., Yanagawa, Y., Obata, K., Sugimoto, Y., and Tamamaki, N. (2008). Method for single-cell microarray analysis and application to gene-expression profiling of GABAergic neuron progenitors. Neurosci. Res. 60, 439-451.

Fairén, A., DeFelipe, J., and Regidor, J. (1984). Nonpyramidal neurons: general account. In Cerebral Cortex, Vol. 1, A. Peters and E. G. Jones, eds (New York, NY, Plenum Press), pp. 201-245.

Flames, N., Pla, R., Gelman, D. M., Rubenstein, J. L. R., Puelles, L., and Marin, O. (2007). Delineation of multiple subpallial progenitor domains by the combinatorial expression of transcriptional codes. J. Neurosci. 27, 9682-9695.

Freund, T. F., and Katona, I. (2007). Perisomatic inhibition. Neuron 56, 33-42.

Fries, P., Womelsdorf, T., Oostenveld, R., and Desimone, R. (2008). The effects of visual stimulation and selective visual attention on rhythmic neuronal synchronization in macaque area V4. J. Neurosci. 28, 4823-4835.

Gabernet, L., Jadhav, S. P., Feldman, D. E., Carandini, M., and Scanziani, M. (2005). Somatosensory integration controlled by dynamic thalamocortical feed-forward inhibition. Neuron 48, 315-327.

Galarreta, M., Erdélyi, F., Szabo, G., and Hestrin, S. (2004). Electrical coupling among irregular-spiking GABAergic interneurons expressing cannabinoid receptors. J. Neurosci. 24, 9700-9778.

Galarreta, M., Erdélyi, F., Szabo, G., and Hestrin, H. (2008). Cannabinoid sensitivity and synaptic properties of 2 GABAergic networks in the neocortex. Cereb. Cortex 18, 2296-2305.

Galarreta, M., and Hestrin, S. (2002). Electrical and chemical synapses among parvalbumin fast-spiking GABAergic interneurons in mouse neocortex. Proc. Natl. Acad. Sci. USA 99, 12438-12443.

Goldberg,J.H.,Lacefield,C.O., andYuste, R. (2004). Global dendritic calcium spikes in mouse layer 5 low threshold spiking interneurones: implications for control of pyramidal cell bursting. J. Physiol. 558, 456-478.

Goldman-Rakic, P.S., and Rakic, P. (1991). Preface: cerebral cortex has come of age. Cereb. Cortex 1, V.

Gonchar, Y., and Burkhalter, A. (1997). Three families of GABAergic neurons in rat visual cortex. Cereb. Cortex 11, 347-358.

Gonchar, Y., and Burkhalter, A. (1999). Differential subcellular localization of forward and feedback interareal inputs to parvalbumin expressing GABAergic neurons in rat visual cortex. J. Comp. Neurol. 406, 346-360.

Gonchar, Y., and Burkhalter, A. (2003). Distinct GABAergic targets of feedforward and feedback connections between lower and higher areas of rat visual cortex. J. Neurosci. 23, 10904-10912.

Gonchar, Y., Wang, Q., and Burkhalter, A. (2008). Multiple distinct subtypes of GABAergic neurons in mouse visual cortex identified by triple immunostaining. Front. Neuroanat. 1, 1-11.

Gupta, A., Wang, Y., and Markram, H. (2000). Organizing principles for a diversity of GABAergic interneurons and synapse in the neocortex. Science 287, 273-278.

Halabisky, B, Shen, F., Huguenard, J. R., and Prince, D. A. (2006). Electrophysiological classification of somatostatin-positive interneurons in mouse sensorimotor cortex. $J$. Neurophysiol. 96, 83-845.

Heinzle, J., Hepp, K., and Martin, K. A. (2007). A microcircuit model for the frontal eye fields. J. Neurosci. 27, 9341-9353.

Higo, S., Udaka, N., and Tamamaki, N. (2007). Long-range GABAergic projection neurons in the cat neocortex. J. Comp. Neurol. 503, 421-431.

Hill, E. L., Gallopin, T., Ferezou, I., Cauli, B., Rossier, J., Schweitzer, P., and Lambolez, B. (2007). Functional CB1 receptors are broadly expressed in neocortical GABAergic and glutamatergic neurons. J. Neurophysiol. 97, 2580-2589.
Hof, P. R., Glezer, I., Conde, F., Flagg, R. A., Rubin, M. B., Nimchinsky, E. A. and Vogt Weisenhorn, D. M. (1999). Cellular distribution of the calciumbinding proteins parvalbumin, calbindin, and calretinin in the neocortex of mammals: phylogenetic and developmental patterns. J. Chem. Neuroanat. 16, 77-116.

Houser,C.R., Vaughn,J.E.,Hendry, S. H. C. Jones, E. G., and Peters, A. (1984). GABA neurons in the cerebral cortex. In Cerebral Cortex, Vol. 2, E. G. Jones and A. Peters, eds (New York, NY, Plenum Press), pp. 63-89.

Huang, Z. J., Di Cristo, G., and Ango, F. (2007). Development of GABA innervation in the cerebral and cerebellar cortices. Nat. Rev. Neurosci. 8 , 673-686.

Hubel, D. H., and Wiesel, T. N. (1979) Brain mechanisms of vision. Sci. Am. 241, 130-144.

Jiao, Y., Zhang, C., Yanagawa, Y., and Sun, Q. Q. (2006). Major effects of sensory experiences on the neocortical inhibitory circuits. J. Neurosci. 26 8691-8701.

Jinno, S., Klausberger, T., Martin, L. F., Dalezios, Y., Roberts, J. D. B. Fuentealba, P.,Bushong,E.A.,Henze, D. Buszáki, G., and Somogyi, P. (2008) Neuronal diversity in GABAergic longrange projections from the hippocampus. J. Neurosci. 27, 8790-8804.

Jones, E. G. (1984). Neurogliaform or spiderweb cells. In Cerebral Cortex, Vol. 1, A. Peters and E. G. Jones, eds (New York, NY, Plenum Press), pp 409-417.

Jones, E. G., and Hendry, S. C. H. (1984) Basket cells. In Cerebral Cortex, Vol. 1, A. Peters and E. G. Jones, eds (New York, NY, Plenum Press), pp. 309-334.

Kalanithi, P. S., Zheng, W., Katoka, Y., DiFiglia, M., Grantz, H., Saper, C. B. Schwartz, M. L., Leckman, J. F., and Vaccarino, F. M. (2005). Altered parvalbumin-positive neuron distribution in basal ganglia of individuals with Tourette syndrome. Proc. Natl. Acad. Sci. USA 102, 13307-13312.

Kapfer, C., Glickfield, L. L. Atallah, B. V., and Scanziani, M. (2007). Supralinear increase of recurrent inhibition during sparse activity in the somatosensory cortex. Nat. Neurosci. 10, 743-753.

Karube, F., Kubota, Y., and Kawaguchi, Y. (2004). Axon branching and synaptic bouton phenotypes in GABAergic nonpyramidal cell subtypes. J. Neurosci. 24, 2853-2865.

Kawaguchi, Y. (1993). Groupings of nonpyramidal and pyramidal cells with specific physiological and morphological characteristics in rat frontal cortex. J. Neurophysiol. 69, 416-431.
Kawaguchi, Y., and Kondo, S. (2002). Parvalbumin, somatostatin and cholecystokinin as chemical markers for specific GABAergic interneuron types in the rat frontal cortex. J. Neurocytol. 31, 277-287.

Kawaguchi, Y., and Kubota, Y. (1993). Correlation of physiological subgroupings of nonpyramidal cells with specific physiological and morphological characteristics in rat frontal cortex. J. Neurophysiol. 70, 387-396.

Kawaguchi, Y., and Kubota, Y. (1996). Physiological and morphological identification of somatostatin- or vasoactive intestinal polypeptide-containing cells among GABAergic cell subtypes in rat frontal cortex. J. Neurosci. 16, 2701-2715.

Kawaguchi, Y., and Kubota, Y. (1997). GABAergic cell subtypes and their synaptic connections in rat frontal cortex. Cereb. Cortex 7, 476-486.

Kisvárday,Z. (1992). GABAergic networks of basket cells in the visual cortex. Prog. Brain Res. 90, 385-405.

Klausberger, T., and Somogyi, P. (2008). Neuronal diversity and temporal dynamics: The unity of hippocampal circuit operations. Science 321, 53-57.

Krimer, L. S., Zaitsev, A. V., Czanner, G., Kröner, S., Gonzalez-Burgos, G., Povysheva, N. V., Iyengar, S., Barrinuevo, G., and Lewis, D. A. (2005). Cluster analysis-based physiological classification and morphological properties of inhibitory neurons in layers203 of monkey dorsolateral prefrontal cortex. J. Neurophysiol. 94 , 3009-3022.

Kubota, Y., Hattori, R., and Yui, Y. (1994). Three distinct subpopulations of GABAergic neurons in rat frontal agranular cortex. Brain Res. 649 , 159-173.

Kubota, Y., and Kawaguchi, Y. (1997). Two distinct subgroups of cholecystokinin immunoreactive cortical interneurons. Brain Res. 752, 175-183.

Kuhlman, S. J., and Huang, Z. J. (2008). High-resolution labeling and functional manipulation of specific neuron types in mouse brain by Cre-activated viral gene expression. PLoS ONE 3 , $1-11$

Lenhossék, M.V.(1895).Der feine Bau des Nervensystems. Berlin, Fischer.

Lewis, D. A., and Gonzalez-Burgos, G. (2008). Neuroplasticity of neocortical circuits in schizophrenia. Neuropharmacology 33, 141-165.

Lewis, D. A., and Lund, J. S. (1990). Heterogeneity of chandelier neurons in monkey neocortex: corticotropinreleasing factor- and parvalbuminimmunoreactive populations. J. Comp. Neurol. 293, 599-615. 
Lorente de No, R. (1992). The cerebral cortex of the mouse. Somatosens. Mot. Res. 9, 3-36.

Ma,Y., Hu, A., Berrebi,A.S., Mathers, P. H., and Agmon, A. (2006). Distinct subtypes of somatostatin-containing neocortical interneurons revealed in transgenic mice. J. Neurosci. 26, 5069-5082.

Markram, H., Toledo-Rodriguez, M., Wang, Y., Gupta, A., Silberberg, G., and $\mathrm{Wu}, \mathrm{C}$. (2004). Interneurons of the neocortical inhibitory system. Nat. Rev. Neurosci. 5, 793-807.

McCormick, D. A., Connors, B. W., Lighthall, J. W., and Prince, D. A. (1985). Comparative electrophysiology of pyramidal and sparsely spiny stellate neurons of the neocortex. $J$. Neurophysiol. 54, 782-806.

McDonald, C. T., and Burkhalter, A. (1993). Organization of long-range inhibitory connections within rat visual cortex. J. Neurosci. 13, 768-781.

Miyoshi, G., Butt, S. J., Takebayashi, H., and Fishell, G. (2007). Physiologically distinct temporal cohorts of cortical interneurons arise from telencephalic Olig2-expressing precursors. J. Neurosci. 27, 7786-7798.

Nelson, S. B., Sugino, K., and Hempel, C. M. (2006). The problem of neuronal cell types: a physiological genomics approach. Trends Neurosci. 29, 339-345.

Nowak, L. G., Azouz, R., SanchezVivez, M. V., Gray, C. M., and McCormick, D. A. (2003). Electrophysiological classes of cat primary visual cortical neurons in vivo as revealed by quantitative analyses. $J$. Neurophysiol. 89, 1541-1566.

Ohki, K., and Reid, C. R. (2007).Specificity and randomness in the visual cortex. Curr. Opin. Neurobiol. 17, 401-407.

Oliva,A.A., Jiang, M., Lam, T., Smith, K. L., and Swann, J. W. (2000). Novel hippocampal interneuronal subtypes identified using transgenic mice that express green fluorescent protein in GABAergic interneurons. J. Neurosci. 20, 3354-3368.

Parra, P., Gulyás, A. I., and Miles, R. (1998). How many subtypes of inhibitory cells in the hippocampus? Neuron 20, 983-993.

Peters, A. (1984a). Chandelier cells. In Cerebral Cortex, Vol. 1, A. Peters and E. G. Jones, eds (New York, NY, Plenum Press), pp. 361-379.

Peters, A. (1984b). Bipolar cells. In Cerebral Cortex, Vol. 1, A. Peters and E. G. Jones, eds (New York, NY, Plenum Press), pp. 381-405.

Peters, A., Payne, B. R., and Josephson, K. (1990). Transcallosal non-pyramidal cell projections from visual cor- tex in the cat. J. Comp. Neurol. 302, 124-142.

Porter, J. T., Johnson, C. K., and Agmon, A. (2001). Diverse types of interneurons generate thalamus-evoked feedforward inhibition in the mouse barrel cortex. J. Neurosci. 21, 2699-2710.

Rakic, P. (1976). Local Circuit Neurons, Cambridge, MIT press, pp. 5-19.

Ramón y Cajal, S. (1899). Apuntes para el estudio estructural de la corteza visual del cerebro humano. Rev. Iberoam Cienc. Med. 1, 1-14.

Ramón y Cajal, S. (1904). Textura del sistema nervioso del hombre y de los vertebrados. Madrid, Imprenta N. Moya.

Reyes, A., Lujan, R., Rozov, A., Burnashev, N., Somogyi, P., and Sakmann, B. (1998). Target-cellspecific facilitation and depression in neocortical circuits. Nat. Neurosci. 1, 279-285.

Schwaller,B.,Meyer,M., and Schiffmann, S. (2002). 'New' functions for 'old' proteins: the role of the calcium binding proteins calbindin D-28k, calretinin and parvalbumin in cerebellar physiology. Studies with knockout mice. Cerebellum 1, 241-258.

Shao, Z., and Burkhalter, A. (1996). Different balance of excitation and inhibition in forward and feedback circuits of rat visual cortex. J. Neurosci. 16, 7353-7365.

Shu, Y., Hasenstaub, A., and McCormick, D. A. (2003). Turning on and off recurrent balanced a cortical activity. Nature 423, 288-293.

Silberberg, G., and Markram, H. (2007). Disynaptic inhibition between neocortical pyramidal cells mediated by Martinotti cells. Neuron 53, 735-746.

Somogyi, P. (1977).A specific'axo-axonal' interneuron in the visual cortex of the rat brain. Brain Res. 136, 354-350.

Somogyi, P., and Cowey, A. (1984). Double bouquet cells. In Cerebral Cortex, Vol. 1, A. Peters and E. G. Jones, eds (New York, NY, Plenum Press), pp. 337-358.

Somogyi, P., and Klausberger, T. (2005). Defined types of cortical interneurone structure space and spike timing in the hippocampus. J. Physiol. 562, 9-25.

Staiger, J. F., Zilles, K., and Freund, T. F. (1996). Distribution of GABAergic elements postsynaptic to ventroposteromedial thalamic projections in layer IV of rat barrel cortex. Eur. J. Neurosci. 8, 2273-2285.

Stevens, C. F. (1998). Neuronal diversity: too many cell types for comfort. Curr. Biol. 8, R708-R710.

Sugino, K., Hempel, C. M., Miller, M. N., Hattox, A. M., Shapiro, P., Wu, C., Huang, Z. J., and Nelson, S. B. (2006).
Molecular taxonomy of major neuronal classes in the adult mouse forebrain. Nat. Neurosci. 9, 99-107.

Sun, Q.-Q., Huguenard, J. R., and Prince, D. A. (2006). Barrel cortex microcircuits: thalamocortical feedforward inhibition in spiny stellate cells in mediated by a small number of fast-spiking interneurons. J. Neurosci. 26, 1219-1230.

Swadlow, H. A. (2003). Fast-spike interneurons and feedforward inhibition in awake sensory neocortex. Cereb. Cortex 13, 25-32.

Szabadics, J., Varga, C., Molnár, G., Olah, S., Barzó, P., and Tamás, G. (2006). Excitatory effect of GABAergic axo-axonic cells in cortical microcircuits. Science 311, 233-235.

Tabuchi, K., Blundell, J., Etherton, M. R., Hammr, R. E., Liu, X., Powell, C. M. and Südhof, T. C. (2007). A neuroligin-3 mutation implicated in autism increases inhibitory synaptic transmission in ice. Science 318, 71-76.

Tamás, G., Lörincz, Simon, A., and Szabadics, J. (2003). Identified sources and targets of slow inhibition in the neocortex. Science 299, 1902-1905.

Tan,Z.,Hu,H.,Huang, J.Z., and Agmon, A. (2008). Robust but delayed thalamocortical activation of dendritic-targeting inhibitory interneurons. Proc. Natl. Acad. Sci. USA 105, 2187-2192.

Thomson, A. M., and Deuchars, J. (1997). Synaptic interactions in neocortical local circuits: dual intracellular recordings in vitro. Cereb. Cortex 7 510-522.

Thomson, A. M, and Lamy, C. (2007) Functional maps of neocortical local circuits. Front. Neurosci. 1, 19-42.

Thomson, A. M., West, D. C., Wang, Y., and Bannister, A. P. (2002). Synaptic connections and small circuits involving excitatory and inhibitory neurons in layers $2-5$ of adult rat and cat neocortex: triple intracellular recordings and biocytin labeling in vitro. Cereb. Cortex 12, 936-953.

Toledo-Rodriguez, M., Goodman, P., Illic, M., Wu, C., and Markram, H (2005). Neuropeptide and calciumbinding protein gene expression profiles predict neuronal anatomical type in the juvenile rat. J. Physiol. 567, 401-413.

Tomioka, R., Okamoto, K., Furuta, T., Fujiyama, F., Iwasato, T., Yanagawa, Y., Obata,K.,Kaneko,T.,and Tamamaki, N. (2005). Demonstration of long-range GABAergic connections distributed throughout mouse neocortex. Eur. J. Neurosci. 21, 1587-1600.

Tomioka, R., and Rockland, K. S. (2007). Long-distance corticocortical GABAergic neurons in the adult mon- key white and gray matter. J. Comp. Neurol. 505, 526-538.

Uematsu, M., Hirai, Y., Karube, K., Ebihara, S., Kato, M., Abe, K., Obata, K., Yoshida, S., Hirabayashi, M., Yanagwa, Y., and Kawaguchi,Y.(2008). Quantitative chemical composition of cortical GABAergic neurons revealed in transgenic venus-expressing rats. Cereb. Cortex 18, 315-330.

Van Brederode, J. F. M., Mulligan, K. A., and Hendrickson, A. E. (1990). Calcium-binding proteins as markers for subpopulations of GABAergic neurons in monkey striate cortex. $J$. Comp. Neurol. 298, 1-22.

von Engelhardt, J., Eliava, M., Meyer, A. H., Rozov, A., and Monyer, H. (2007). Functional characterization of intrinsic cholinergic interneurons in the cortex. J. Neurosci. 27, 5633-5642.

Vruwink, M., Schmidt, H. H. H. W., Weinberg, R. J., and Burette,A. (2001). Substance $\mathrm{P}$ and nitric oxide signaling in cerebral cortex: anatomical evidence for reciprocal signaling between two classes of interneurons. J. Comp. Neurol. 441, 288-301.

Wang,Y., Gupta,A., Toledo-Rodriguez, M., Wu, C. Z., and Markram, H. (2002). Anatomical, physiological, molecular and circuit properties of nest basket cells in the developing somatosensory cortex. Cereb. Cortex 12, 395-410.

Wang,Y., Toledo-Rodriguez,M., Gupta, A., Wu, C., Silberberg, G., Luo, J., and Markram, H. (2004). Anatomical, physiological and molecular properties of Martinotti cells in the somatosensory cortex of the juvenile rat. J. Physiol. 561, 65-90.

West, D. C., Mercer, A., Kirchhecker, S., Morris, O. T., and Thomson, A. M. (2006). Layer 6 cortico-thalamic pyramidal cells preferentially innervate interneurons and generate facilitating EPSPs. Cereb. Cortex 16, 200-211.

White, E. L. (1978). Identified neurons in mouse Sml cortex with are postsynaptic to thalamocortical axon terminals: a combined Golgi-electron microscopic and degeneration study. J. Comp. Neurol. 181, 627-661.

Wolansky, T., Pagliardini, S., Greer, J. J., and Dickson, C. T. (2007). Immunohistochemical characterization of substance $\mathrm{P}$ receptor $(\mathrm{NK}(1)$ $\mathrm{R})$-expressing interneurons in the entorhinal cortex. J. Comp. Neurol. 502, 427-441.

Womelsdorf, T., Schoffelen, J. M., Oostenveld, R., Singer, W., Desimone, R., Engel, A. K., and Fries, P. (2007). Modulation of neuronal interactions through neuronal synchronization. Science 316, 1609-1612.

Wonders, C. P., and Anderson, S.A. (2006). The origin and specification of corti- 
cal interneurons. Nat. Rev. Neurosci. 7, 687-696.

Xu, X., Roby, K. D., and Callaway, E. M. (2006). Mouse cortical inhibitory neuron type that coexpresses somatostatin and calretinin. J. Comp. Neurol. 499, 144-160.

Yamashita,A., Valkova, K., Gonchar, Y., and Burkhalter, A. (2003). Rearrangement of synaptic connections with inhibitory neurons in developing mouse visual cortex. J. Comp. Neurol. 464, 426-437.

Yoshimura, Y., and Callaway, E. M. (2005). Fine-scale specificity of cortical net- works depends on inhibitory cell type and connectivity. Nat. Neurosci. 8, 1552-1559.

Yoshimura, Y., Dantzker, J. M., and Callaway, E. M. (2005). Excitatory cortical neurons form fine-scale functional networks. Nature 433, 868-873.

Yuste, R. (2005). Origin and classification of neocortical interneurons. Neuron 48, 524-527.

Zaitsev, A. V., Gonzalez-Burgos, G., Povysheva, N. V., Kroner, S., Lewis, D. A., Krimer, L. S. (2005). Localization of calcium-binding pro- teins in physiologically and morphologically characterized interneurons of monkey dorsolateral prefrontal cortex. Cereb. Cortex 15, 1178-1186.

Zhu, J. J., and Connors, B. W. (1999). Intrinsic firing patterns and whiskerevoked synaptic responses of neurons in the rat barrel cortex. J. Neurophysiol. 81, 1171-1183.

Conflict of Interest Statement: This article was prepared in the absence of any commercial financial relationships that could be construed as potential conflict of interest.
Received: 06 July 2008; accepted: 18 September 2008; published: 15 December 2008.

Citation: Front. Neurosci. (2008) 2, 2:

155-167. doi: 10.3389/neuro.01.026.2008 Copyright: (c) 2008 Burkhalter. This is an open-access article subject to an exclusive license agreement between the authors and the Frontiers Research Foundation, which permits unrestricted use, distribution, and reproduction in any medium, provided the original authors and source are credited. 